\title{
Temporal trends in diabetic ketoacidosis at diagnosis of paediatric type 1 diabetes between 2006 and 2016: results from 13 countries in three continents
}

\author{
Valentino Cherubini ${ }^{1}$ (D) - Julia M. Grimsmann ${ }^{2,3}$ (D) $\cdot$ Karin Åkesson $^{4,5}$ (D) Niels H. Birkebæk ${ }^{6}$ (D) Ondrej Cinek $^{7}$ (D) \\ Klemen Dovč ${ }^{8}$ (D) $\cdot$ Rosaria Gesuita $^{9}$ (D) - John W. Gregory ${ }^{10}$ (D) Ragnar Hanas $^{11,12}$ (D) Sabine E. Hofer ${ }^{13}$ (D) \\ Reinhard W. Holl ${ }^{2,3}$ (D) Craig Jefferies $^{14}$ (D) Geir Joner $^{15,16}$ (D) Bruce R. King ${ }^{17}$ (D) Elizabeth J. Mayer-Davis ${ }^{18}$ (D) \\ Alexia S. Peña ${ }^{19}$ (D) Birgit Rami-Merhar ${ }^{20}$ (D) - Ulrike Schierloh ${ }^{21}$ (D) Torild Skrivarhaug $^{15,16}$ (D) Z Zdenek Sumnik ${ }^{7}$ (D) \\ Jannet Svensson ${ }^{22}$ (D) Justin T. Warner ${ }^{23} \cdot$ Nataša Bratina $^{8}$ (D) $\cdot$ Dana Dabelea $^{24}$ (D)
}

Received: 25 November 2019 / Accepted: 9 March 2020 / Published online: 8 May 2020

(C) The Author(s) 2020

\begin{abstract}
Aims/hypothesis The aim of this work was to evaluate geographical variability and trends in the prevalence of diabetic ketoacidosis (DKA), between 2006 and 2016, at the diagnosis of childhood-onset type 1 diabetes in 13 countries over three continents.

Methods An international retrospective study on DKA at diagnosis of diabetes was conducted. Data on age, sex, date of diabetes diagnosis, ethnic minority status and presence of DKA at diabetes onset were obtained from Australia, Austria, Czechia, Denmark, Germany, Italy, Luxembourg, New Zealand, Norway, Slovenia, Sweden, USA and the UK (Wales). Mean prevalence was estimated for the entire period, both overall and by country, adjusted for sex and age group. Temporal trends in annual prevalence of DKA were estimated using logistic regression analysis for each country, before and after adjustment for sex, age group and ethnic minority status.

Results During the study period, new-onset type 1 diabetes was diagnosed in 59,000 children (median age [interquartile range], 9.0 years [5.5-11.7]; male sex, 52.9\%). The overall adjusted DKA prevalence was 29.9\%, with the lowest prevalence in Sweden and Denmark and the highest in Luxembourg and Italy. The adjusted DKA prevalence significantly increased over time in Australia, Germany and the USA while it decreased in Italy. Preschool children, adolescents and children from ethnic minority groups were at highest risk of DKA at diabetes diagnosis in most countries. A significantly higher risk was also found for females in Denmark, Germany and Slovenia.

Conclusions/interpretation DKA prevalence at type 1 diabetes diagnosis varied considerably across countries, albeit it was generally high and showed a slight increase between 2006 and 2016. Increased awareness of symptoms to prevent delay in diagnosis is warranted, especially in preschool children, adolescents and children from ethnic minority groups.
\end{abstract}

Keywords Children with diabetes $\cdot$ Complications $\cdot$ Diabetic ketoacidosis $\cdot$ Diagnosis of diabetes $\cdot$ Epidemiology $\cdot$ Type 1 diabetes

Electronic supplementary material The online version of this article (https://doi.org/10.1007/s00125-020-05152-1) contains peer-reviewed but unedited supplementary material, which is available to authorised users.

Rosaria Gesuita

r.gesuita@univpm.it

Julia M. Grimsmann

julia.hermann@uni-ulm.de

Extended author information available on the last page of the article

\section{Abbreviations}

ADDN Australasian Diabetes Data Network

DKA Diabetic ketoacidosis

GDP Gross domestic product

HDI Human development index 


\section{Research in context}

\section{What is already known about this subject?}

- Reported prevalence estimates of diabetic ketoacidosis (DKA) at diagnosis vary between countries

- The burden of DKA at diagnosis remains high in many countries

- DKA at diagnosis of diabetes has not been compared in an international setting

\section{What is the key question?}

- Is the prevalence of DKA at diagnosis of type 1 diabetes reducing over time?

\section{What are the new findings?}

- Based on the analysis of 59,000 children with newly diagnosed type 1 diabetes, from 13 countries in three continents, over an 11 year period from 2006 to 2016, DKA prevalence at type 1 diabetes diagnosis varies considerably across countries

- In addition, DKA prevalence was shown to still be unacceptably high in 2016 and showed a slight increase between 2006 and 2016

\section{How might this impact on clinical practice in the foreseeable future?}

- These data must be considered worrying for all countries, especially for those with advanced healthcare systems, and demonstrate the following points: (1) collaborative approaches help to gain a better understanding of the prevalence of DKA at diagnosis of diabetes and may help to inform development of interventions to improve patient outcomes; and (2) there is a need for more objective evaluation of DKA, including venous $\mathrm{pH}$, allowing better estimates of DKA in all children with a new diagnosis of type 1 diabetes

\section{Introduction}

Clinical presentation of type 1 diabetes is often associated with diabetic ketoacidosis (DKA), which may lead to increased morbidity and mortality risk and healthcare expenditure [1]. DKA at diabetes diagnosis may arise from delayed diagnosis due to lack of awareness of diabetes symptoms or failure of a healthcare provider to consider diabetes when a child presents with abdominal pain, nausea and vomiting [2]. It is associated with both long-term poor glycaemic control and subsequent recurrent episodes of DKA [3-6]. DKA at diabetes diagnosis is also associated with long-term spatial memory performance and is associated with lower cognitive scores and altered brain growth $[7,8]$.

Screening of genetic risk and beta cell autoantibodies in high-risk individuals allows an early diagnosis of type 1 diabetes [9-12] and, consequently, possible prevention of DKA at diabetes diagnosis. However, a cost-benefit analysis of a screening programme in the general population showed that costs far outweighed the economic benefits [13]. The impact of individual knowledge and community-based information and education campaigns in reducing DKA at type 1 diabetes onset has been disappointing [14-16]. These studies have suggested that knowledge of the symptoms of diabetes does not necessarily appear to translate to an earlier diagnosis. It is worthwhile noting that even, in the T1D Exchange registry [17], a relatively high percentage of children who had a parent with type 1 diabetes (and, hence, knowledge of the classic symptoms of diabetes) presented with DKA (24\%). Community education programmes, in which DKA was reduced when compared with a nointervention group, were intensive and also specifically targeted primary care physicians, teachers and early childhood workers, using face-to-face education and written action plans [18, 19]. On the other hand, other studies identified clinical and sociodemographic factors associated with the presence of DKA at diabetes onset $[20,21]$, suggesting specific targets for intervention to raise awareness of the disease.

Reported prevalence estimates of DKA at diabetes diagnosis vary between countries and there is some evidence that prevalence is associated with a country's socioeconomic factors [22]. However, the definitions of DKA, reporting of venous $\mathrm{pH}$ in medical records, inclusion criteria, age ranges of individuals included and statistical analyses differ considerably between studies [22].

Despite improvements in medical care over the years, and in diabetes care after diabetes onset, the burden of DKA at diagnosis remains high in many countries [14, 23-25]. DKA in individuals with known diabetes has been compared in an international setting, but DKA prevalence at diagnosis of type 1 diabetes has not [26]. Therefore, the aim of this study was to evaluate worldwide geographical variability and time trends 
in the prevalence of DKA at diagnosis of childhood-onset type 1 diabetes during 2006-2016, in developed healthcare systems, according to country, sex, age and ethnic minority status.

\section{Methods}

Study population An international collaboration proposed a retrospective, population-based study on DKA at type 1 diabetes diagnosis during 2006-2016, in children aged 6 months to 14.9 years. This upper age limit was chosen since most registries for type 1 diabetes include children under 15 years of age. Children under 6 months of age were not included to exclude cases of neonatal diabetes. Requirements for participating countries included nationwide or regional availability of data for at least 6 consecutive years in the study period, and willingness to share anonymised patient-level data for joint analysis.

DKA was defined according to the International Society for Pediatric and Adolescent Diabetes (ISPAD) criteria (venous $\mathrm{pH}<7.3$ or serum bicarbonate $<15 \mathrm{mmol} /$ ) ) or documented information on DKA (yes/no) according to the physician providing medical care at diagnosis.

Data collection Required data per individual included were age, date of diabetes diagnosis, sex, ethnic minority status (if available), and venous $\mathrm{pH}$, serum bicarbonate, or information on DKA (yes/no).

Thirteen countries participated in the project (Fig. 1): ten countries from Europe (Austria, Germany and Luxembourg [Diabetes Patients Follow-up registry (DPV)], Czechia [Czech National Childhood Diabetes Register (ČENDA)], Denmark [Danish Registry of Childhood and Adolescent Diabetes (DanDiabKids)], Italy [Study Group for diabetes of the Italian Society for Paediatric Endocrinology and Diabetes], Norway [Norwegian Childhood Diabetes Registry (NCDR)], Slovenia [Slovenian national diabetes type 1 registry], Sweden [The Swedish Paediatric Diabetes Quality Registry, SWEDIABKIDS] and the UK [Wales; The Brecon Group Register and Brecon Cohort (Welsh Paediatric Diabetes Interest Group)]); two regions from Australasia (Auckland, New Zealand and Australia [Australasian Diabetes Data Network (ADDN)]); and a consortium of sites from the USA (SEARCH for Diabetes in Youth-US).

The European participating centres defined ethnic minority status as at least one parent born outside the country with a positive migration history, or using a list of ethnic categories (African, Asian, mixed). The USA (SEARCH) included in ethnic minority status all races/ethnicities other than nonHispanic white. The New Zealand (Auckland) centre defined ethnic minority status as Māori, Pacific Islander, Indian, South-East Asian, African or Middle Eastern ethnicities. The Australian centres included in ethnic minority status,

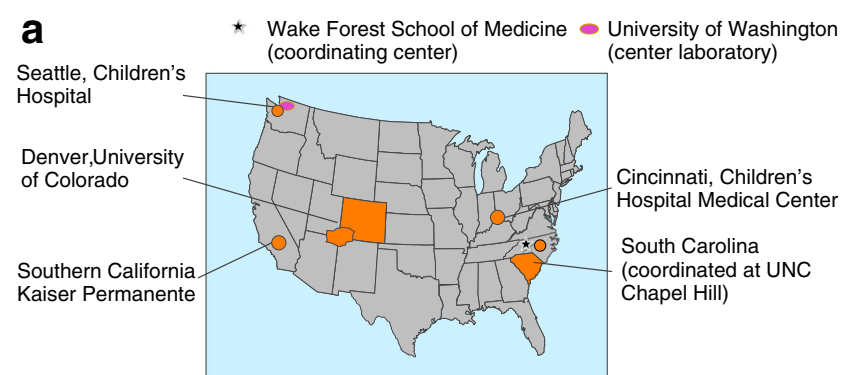

b

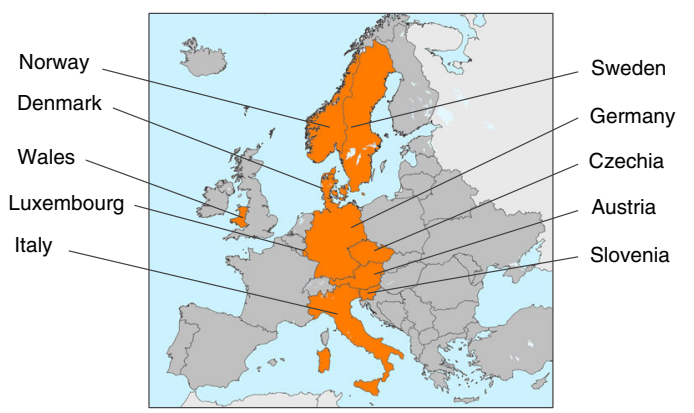

C

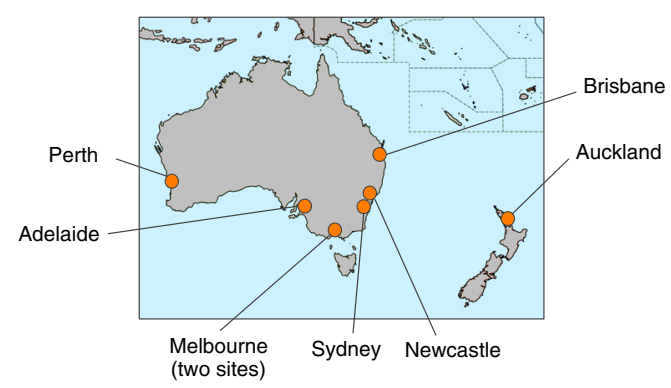

Fig. 1 Map showing 13 centres from three continents (a) the USA, (b) Europe and (c) Australasia, participating in the DKA international collaboration project (whole nations, administrative units or clinic centres are shown). Maps by https://vemaps.com/, adapted by the authors

Aboriginal and Torres Strait Islander people and immigrants from a non-Anglo background.

Data sources Data sources consisted of population-based registries (Australia, New Zealand [Auckland], Austria, Czechia, Denmark, Germany, Luxembourg, Norway, Slovenia, Sweden, Wales), nationwide clinical records (Italy) and a national multicentre study (USA [SEARCH]) with a completeness of coverage of at least $90 \%$ during the study period, as previously described [21, 25, 27-33]. All data owners gave the permission for publication. Data were collected from each country and integrated in a joint SAS database.

To evaluate the association of DKA prevalence with gross domestic product (GDP) per capita and human development index (HDI), the mean GDP and HDI for the 13 participating countries were extracted for 2006-2016 from the reports of the United Nations Development Programme [34]. HDI measures the development of a country using three dimensions, namely life expectancy at birth, expected years of schooling and the gross national income per capita. The 
Table 1 Cases of type 1 diabetes, DKA prevalence and standardised DKA prevalence, at type 1 diabetes diagnosis across the study population between 2006 and 2016

\begin{tabular}{llll}
\hline Country & $\begin{array}{l}\text { New diagnosis } \\
\text { of type 1 diabetes }(n)\end{array}$ & $\begin{array}{l}\text { DKA prevalence, } \\
\%(95 \% \text { CI })\end{array}$ & $\begin{array}{l}\text { Standardised DKA } \\
\text { prevalence, \% (95\% CI) }\end{array}$ \\
\hline Australia (ADDN) & 4428 & $24.9(23.6,26.2)$ & $24.9(23.4,26.4)$ \\
Austria & 1504 & $38.0(35.6,40.5)$ & $37.7(34.6,40.7)$ \\
Czechia & 2261 & $28.8(27.0,30.7)$ & $28.6(26.4,30.8)$ \\
Denmark & 3084 & $20.7(19.3,22.1)$ & $20.8(19.1,22.4)$ \\
Germany & 19,127 & $26.8(26.2,27.4)$ & $26.8(26.1,27.5)$ \\
Italy & 10,317 & $41.2(40.3,42.2)$ & $41.2(39.9,42.4)$ \\
Luxembourg & 192 & $43.8(36.9,50.9)$ & $43.8(34.5,53.2)$ \\
New Zealand (Auckland) & 670 & $26.3(23.1,29.7)$ & $26.3(22.4,30.2)$ \\
Norway & 3331 & $22.1(20.7,23.5)$ & $22.1(20.5,23.7)$ \\
Slovenia & 471 & $40.3(36.0,44.8)$ & $39.9(34.2,45.6)$ \\
Sweden & 6457 & $19.5(18.6,20.5)$ & $19.5(18.4,20.6)$ \\
USA (SEARCH) & 5485 & $36.9(35.6,38.1)$ & $37.0(35.4,38.6)$ \\
UK (Wales) & 1673 & $25.0(23.0,27.2)$ & $25.0(22.6,27.4)$ \\
All countries combined & 59,000 & $29.2(28.8,29.6)$ & \\
\hline
\end{tabular}

${ }^{\text {a }}$ Standardised on whole study population association between DKA prevalence and countries' latitudes was also analysed.

Statistical analysis DKA at diagnosis of type 1 diabetes was evaluated as raw and standardised prevalence and 95\% CI. The prevalence of DKA was standardised by sex and age over the whole study population using the direct method. Raw and standardised prevalences were computed across the entire period, overall and by country.

Mean prevalence was also calculated according to age group and sex. Comparisons between sexes in each age group were performed using the $\chi^{2}$ test. The $p$ values were adjusted for multiple comparisons using the procedure proposed by Benjamini and Hochberg [35].

DKA prevalence by country and year at diagnosis of type 1 diabetes, adjusted for sex and age groups, was estimated using multiple log-binomial regression analysis.

Unadjusted temporal trends in DKA prevalence were estimated using log-binomial regression analysis by country. Next, to explore whether changes in demographics of type 1 diabetes explain the observed trends, we performed multiple logbinomial regression analysis to estimate temporal trends adjusted for sex, age group and ethnic minority status, obtaining prevalence ratios for annual changes across countries.

The association between prevalence of DKA at diagnosis of diabetes and GDP per capita, HDI and countries' latitude was evaluated by Spearman correlation coefficients, weighted by the number of cases of type 1 diabetes in each country and $95 \%$ CI.

All the statistical analyses were performed using the SAS System vs 9.4 (SAS Institute, Cary, NC, USA). A $p$ value $<0.05$ was defined as statistically significant.

\section{Results}

DKA prevalence at type 1 diabetes diagnosis During the 11 year period, in our cohort, there were 59,000 new diagnoses of type 1 diabetes (median age 9.0 years, interquartile range 5.5-11.7 years). Characteristics of participants are reported in electronic supplementary material (ESM) Table 1; 52.9\% were male and a total of $17,205(29.2 \%$; $95 \%$ CI 28.82, 29.56) children were considered to have had DKA at onset of type 1 diabetes. Table 1 shows the number of children with newly diagnosed type 1 diabetes and raw and standardised DKA prevalence $(95 \% \mathrm{CI})$. The overall mean prevalence of DKA at diagnosis was $29.9 \%$, with six countries (Australia, Denmark, Germany, Norway, Sweden, Wales) reporting significantly lower prevalence of DKA and five countries (Austria, Italy, Luxembourg, Slovenia, USA) significantly higher prevalences. The lowest prevalence was found in Sweden, whereas the

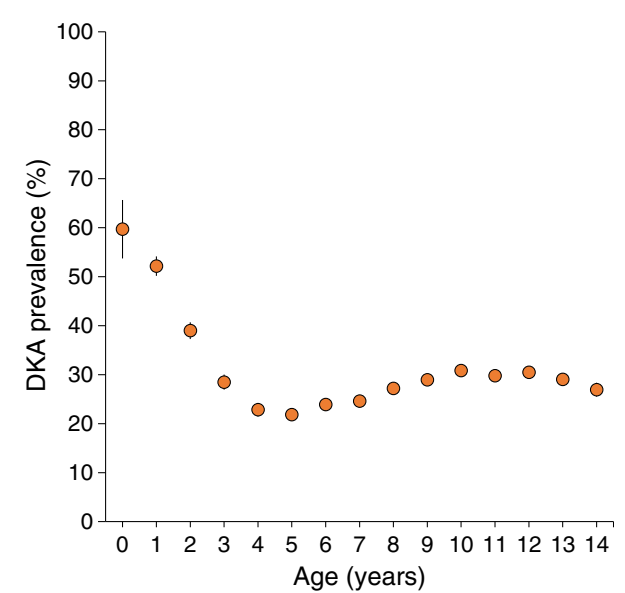

Fig. 2 Mean DKA prevalence (per 100 people) and 95\% CI at type 1 diabetes diagnosis according to year of age (all countries combined) 
Table 2 Mean DKA prevalence (per 100 people) at type 1 diabetes diagnosis across the study population, according to sex and age group

\begin{tabular}{|c|c|c|c|c|c|}
\hline \multirow[t]{2}{*}{ Country } & \multicolumn{2}{|l|}{ Female sex } & \multicolumn{2}{|l|}{ Male sex } & \multirow[t]{2}{*}{$p$ value } \\
\hline & Type 1 diabetes $(n)$ & DKA prevalence $(95 \% \mathrm{CI})$ & Type 1 diabetes $(n)$ & DKA prevalence $(95 \% \mathrm{CI})$ & \\
\hline \multicolumn{6}{|l|}{$0.5-4.9$ years } \\
\hline Australia (ADDN) & 483 & $31.3(26.3,36.2)$ & 561 & $32.6(27.9,37.3)$ & 0.874 \\
\hline Austria & 164 & $45.7(35.4,56.1)$ & 220 & $45.0(36.2,53.8)$ & 0.935 \\
\hline Czechia & 275 & $34.5(27.6,41.5)$ & 316 & $34.5(28.0,41.0)$ & 0.989 \\
\hline Denmark & 241 & $24.5(18.2,30.7)$ & 287 & $17.4(12.6,22.2)$ & 0.153 \\
\hline Germany & 1948 & $33.0(30.5,35.6)$ & 2047 & $31.0(28.6,33.4)$ & 0.450 \\
\hline Italy & 1115 & $51.0(46.8,55.2)$ & 1222 & $50.2(46.2,54.1)$ & 0.874 \\
\hline Luxembourg & 13 & $76.9(46.2,95.5)$ & 24 & $54.2(24.8,83.5)$ & 0.450 \\
\hline New Zealand (Auckland) & 56 & $28.6(14.6,42.6)$ & 63 & $22.2(10.6,33.8)$ & 0.694 \\
\hline Norway & 288 & $24.3(18.6,30.0)$ & 345 & $26.7(21.2,32.1)$ & 0.747 \\
\hline Slovenia & 60 & $53.3(34.9,71.8)$ & 71 & $35.2(21.4,49.0)$ & 0.145 \\
\hline Sweden & 669 & $19.7(16.4,23.1)$ & 755 & $17.2(14.3,20.2)$ & 0.481 \\
\hline USA (SEARCH) & 472 & $41.5(35.7,47.3)$ & 568 & $45.6(40.1,51.1)$ & 0.457 \\
\hline UK (Wales) & 147 & $27.9(19.4,36.4)$ & 169 & $38.5(29.1,47.8)$ & 0.153 \\
\hline All countries combined & 5931 & $35.2(33.7,36.7)$ & 6648 & $34.4(33.0,35.8)$ & 0.326 \\
\hline \multicolumn{6}{|l|}{$5-9.9$ years } \\
\hline Australia (ADDN) & 931 & $24.0(20.8,27.1)$ & 888 & $18.9(16.1,21.8)$ & 0.058 \\
\hline Austria & 247 & $30.8(23.9,37.7)$ & 275 & $32.0(25.3,38.7)$ & 0.874 \\
\hline Czechia & 433 & $25.9(21.1,30.7)$ & 453 & $25.4(20.8,30.0)$ & 0.935 \\
\hline Denmark & 550 & $20.9(17.1,24.7)$ & 537 & $15.6(12.3,19.0)$ & 0.107 \\
\hline Germany & 3528 & $25.4(23.7,27.0)$ & 3570 & $21.8(20.3,23.4)$ & 0.019 \\
\hline Italy & 1937 & $37.2(34.5,39.9)$ & 2009 & $35.6(33.0,38.2)$ & 0.561 \\
\hline Luxembourg & 33 & $54.5(29.4,79.7)$ & 35 & $31.4(12.9,50.0)$ & 0.162 \\
\hline New Zealand (Auckland) & 119 & $22.7(14.1,31.2)$ & 111 & $18.9(10.8,27.0)$ & 0.747 \\
\hline Norway & 591 & $21.5(17.8,25.2)$ & 620 & $14.8(11.8,17.9)$ & 0.030 \\
\hline Slovenia & 82 & $48.8(33.7,63.9)$ & 91 & $25.3(15.0,35.6)$ & 0.026 \\
\hline Sweden & 1154 & $14.9(12.7,17.1)$ & 1178 & $13.8(11.6,15.9)$ & 0.694 \\
\hline USA (SEARCH) & 1056 & $37.2(33.5,40.9)$ & 985 & $32.2(28.6,35.7)$ & 0.083 \\
\hline UK (Wales) & 318 & $17.3(12.7,21.9)$ & 262 & $26.7(20.5,33.0)$ & 0.047 \\
\hline All countries combined & 10,979 & $27.1(26.1,28.1)$ & 11,014 & $24(23.1,24.9)$ & $<0.001$ \\
\hline \multicolumn{6}{|l|}{$10-14.9$ years } \\
\hline Australia (ADDN) & 753 & $22.8(19.4,26.3)$ & 812 & $25.1(21.7,28.6)$ & 0.561 \\
\hline Austria & 255 & $44.7(36.5,52.9)$ & 343 & $35.0(28.7,41.2)$ & 0.083 \\
\hline Czechia & 347 & $27.4(21.9,32.9)$ & 437 & $28.6(23.6,33.6)$ & 0.874 \\
\hline Denmark & 689 & $22.9(19.4,26.5)$ & 780 & $21.9(18.6,25.2)$ & 0.874 \\
\hline Germany & 3510 & $26.5(24.8,28.2)$ & 4524 & $27.5(26.0,29.0)$ & 0.561 \\
\hline Italy & 1775 & $41.5(38.5,44.5)$ & 2259 & $39.6(37.0,42.2)$ & 0.481 \\
\hline Luxembourg & 32 & $34.4(14.1,54.7)$ & 55 & $38.2(21.9,54.5)$ & 0.874 \\
\hline New Zealand (Auckland) & 152 & $32.9(23.8,42.0)$ & 169 & $28.4(20.4,36.4)$ & 0.679 \\
\hline Norway & 645 & $23.9(20.1,27.6)$ & 842 & $23.8(20.5,27.0)$ & 0.981 \\
\hline Slovenia & 82 & $42.7(28.6,56.8)$ & 85 & $41.2(27.6,54.8)$ & 0.935 \\
\hline Sweden & 1183 & $25.0(22.2,27.9)$ & 1518 & $24.3(21.8,26.8)$ & 0.874 \\
\hline USA (SEARCH) & 1083 & $32.4(29.0,35.8)$ & 1321 & $38.2(34.9,41.6)$ & 0.030 \\
\hline UK (Wales) & 363 & $23.7(18.7,28.7)$ & 414 & $24.6(19.9,29.4)$ & 0.874 \\
\hline All countries combined & 10,869 & $29.3(28.3,30.3)$ & 13,559 & $29.8(28.9,30.7)$ & 0.444 \\
\hline
\end{tabular}

${ }^{a} p$ value is adjusted for multiple testing using the Benjamini-Hochberg procedure and it compares DKA prevalence in female sex vs male sex 
highest was observed in Luxembourg. The standardised values were very close to the raw values in all countries, showing a small effect of population structure on DKA prevalence.

ESM Table 2 reports prevalence of DKA and the annual percentage change according to the degree of acidosis for each country, year and for all countries combined. Both moderate DKA and severe DKA overall prevalences showed a small but significant increase over the study period $(1.8 \%$ and $1.6 \%$, respectively). A high variability between countries across the study period was found both for moderate and severe forms of DKA prevalence. Germany and the USA (SEARCH) reported increasing annual percentages in moderate DKA and severe DKA prevalence; Slovenia and Luxembourg reported increasing annual percentages in the moderate and the severe forms, respectively.

Sex and age differences A significantly higher prevalence of DKA was found in girls in Denmark and Slovenia, whereas a higher prevalence was found in boys in Wales (ESM Fig. 1).

Significant differences in mean prevalence of DKA according to age group were found for all countries, except Slovenia; prevalence was higher in children under 5 years of age apart from in Sweden, Denmark and Auckland (New Zealand) where the highest proportions were found in adolescents aged 10-14.9 years (ESM Fig. 2). The overall highest mean prevalence of DKA (34.8\% [95\% CI 34.0, 35.6]) was found in children aged $0.5-4.9$ years, whereas higher proportions were reported in adolescents than in children aged 5-9.9 years $(29.6 \%$ [ $95 \%$ CI $29.0,30.2$ ] vs $25.5 \%$ [95\% CI $24.9,26.1]$, respectively).

As shown in Fig. 2, the overall highest prevalence was observed in children under 1 year of age $(59.7 \%$ [95\% CI $53.7,65.7])$, with a decrease in proportions up until 5 years of age (21.9\% [95\% CI 20.5, 23.2]) and a slow increase thereafter, as children got older, peaking at around 10-12 years of age.

Sex differences were also found by age group (Table 2). No significant differences between boys and girls were found in the 0.5-4.9 year age group whereas higher prevalences in girls in the 5-9.9 year age group in Germany, Norway and Slovenia were reported. A significantly higher prevalence was found in Wales in boys aged 5-9.9 years and in the USA in boys aged $10-14.9$ years.

Ethnic minority status The overall mean prevalence of DKA was higher in children of ethnic minority status $(36.9 \%$ [95\% CI $35.8,38.0], p<0.01)$ than in those of non-minority status (28.4\% [95\% CI 28.0, 28.8]) and this observation was confirmed in most countries, (ESM Fig. 3). No information on ethnic minority status was collected in Czechia and there were no children from an ethnic minority background in Slovenia.
Temporal trend analysis Figure 3 reports the unadjusted annual percentage change in DKA prevalence at type 1 diabetes diagnosis and ESM Fig. 4 the estimated annual standardised prevalence of DKA by country. A slight increasing temporal trend of $0.7 \%$ per year over the period of 11 years for all countries combined was observed. Table 3 shows the results of multiple log-binomial regression analysis. A significant increase in prevalence of DKA at diagnosis of diabetes was found in Australia, Germany and USA, whereas a significant decrease was observed in Italy during the study period.

Girls were at a significantly higher risk of DKA at diagnosis in Denmark, Germany and Slovenia.

A significant negative association between adjusted DKA prevalence and HDI $(r=-0.75$ [95\% CI $-0.90,-0.42])$ and latitude $(r=-0.55$ [95\% CI $-0.81,-0.10])$ was also observed, whereas no significant association was found with GDP per capita $(r=-0.47$ [95\% CI $-0.77,0.01]$ ) (ESM Fig. 5).

\section{Discussion}

The major findings of this international joint project were a high prevalence of children presenting with DKA at diagnosis and a slight increasing trend in prevalence of DKA at diagnosis of type 1 diabetes during 2006-2016 across sites. The project also highlights large inter-country differences and variability in the prevalence of DKA at diabetes diagnosis by age group, sex and ethnic minority status. During the 11 years studied, a marked increase in DKA at diabetes diagnosis was clear in the USA (SEARCH) and Australia (ADDN), while in Germany the increase was small but statistically significant due to the large number of patients from this country. In particular, increasing burden of DKA among both youth [36] and adults [37] was also reported in recent years. The proportion of children presenting with DKA at diagnosis of diabetes decreased in Italy over the study years. However, Italy showed one of the highest prevalences of DKA. The overall increase in DKA prevalence, although small, is indicative of a general phenomenon that remains constantly high over time and shows no sign of decreasing.

Several studies indicate that DKA is associated with a delay in diagnosis $[2,38]$ and many children presenting with DKA have had a medical encounter before diagnosis [2]. Increased disease awareness allows for an earlier diagnosis of type 1 diabetes, likely preventing the occurrence of DKA, as suggested by the lower proportion of children diagnosed with DKA in countries where the incidence of type 1 diabetes is higher $[24,38,39]$. In addition, screening programmes for diabetes $[11,40,41]$ as well as publicity campaigns [18] have been considered effective in reducing DKA prevalence at type 1 diabetes diagnosis. However, awareness campaigns targeted to prevent DKA at type 1 diabetes diagnosis have not shown uniform results. A reduction in DKA prevalence was reported 

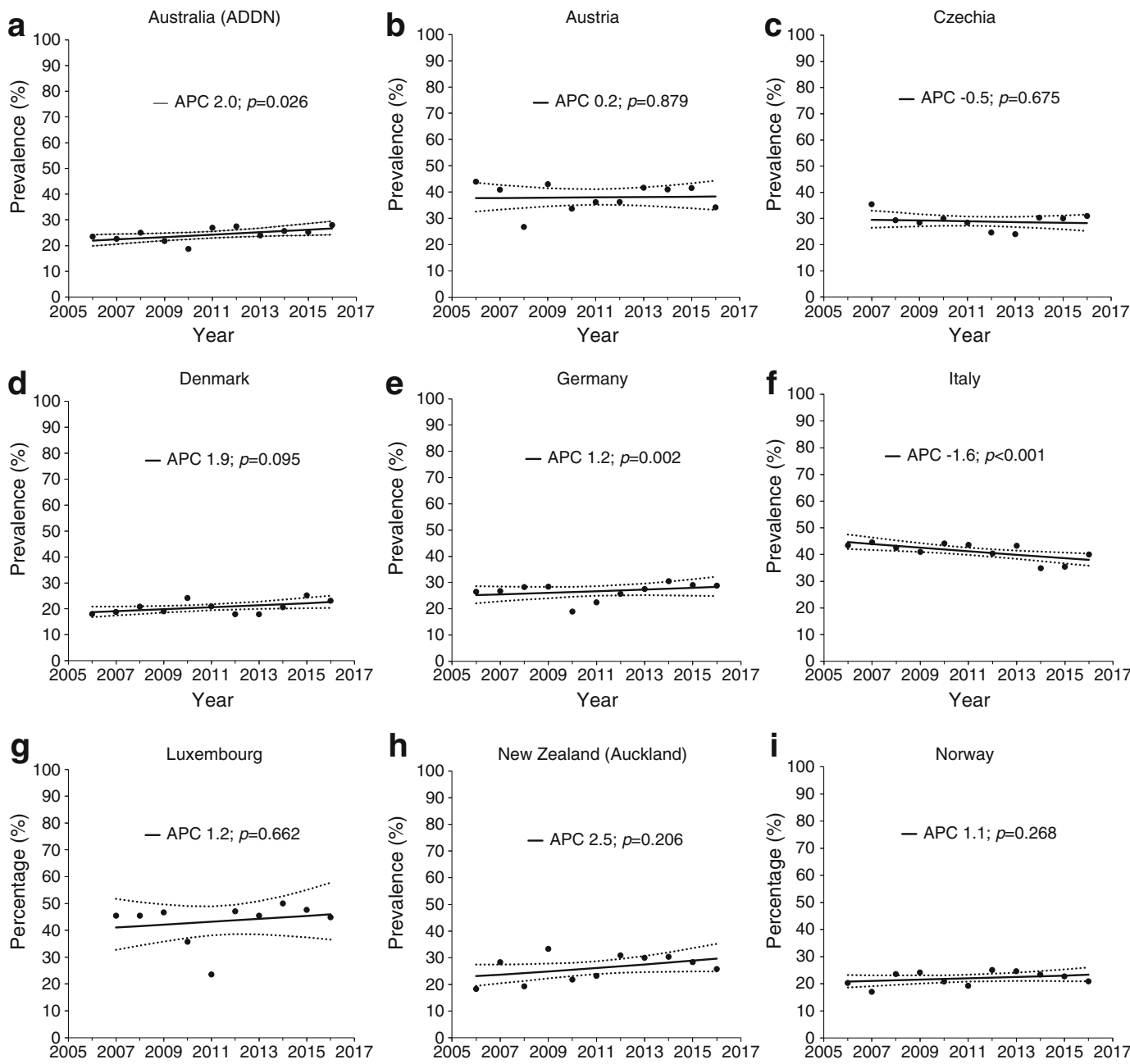

h
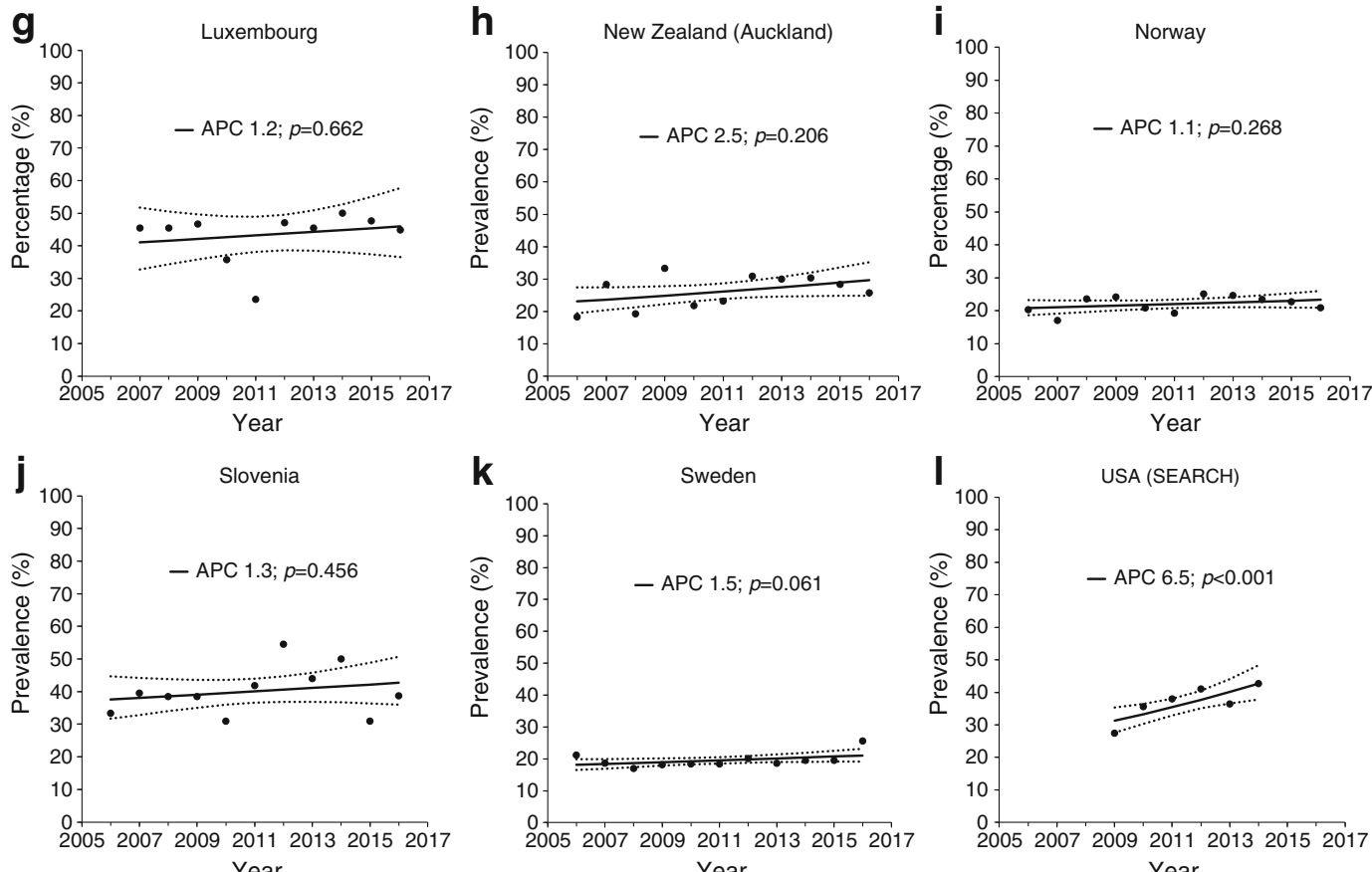

k Year

I
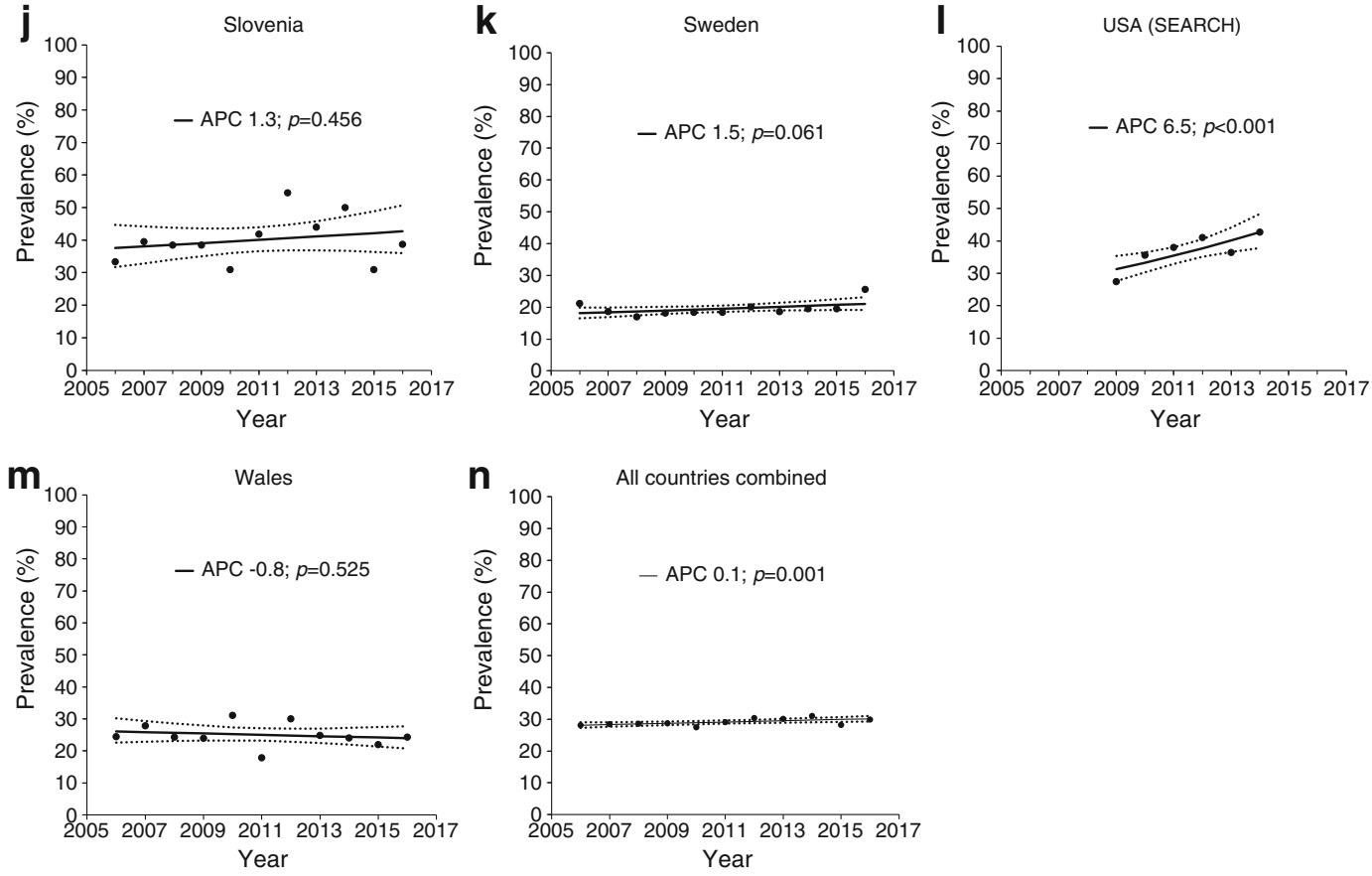

Fig. 3 Annual DKA prevalence (per 100 people) at type 1 diabetes diagnosis and estimated annual percentage change (APC) for each country

and all countries combined, during 2006-2016. Solid line, estimated prevalence trend; dashed line, $95 \%$ CI of estimated prevalence trend 
Table 3 Time trend for DKA prevalence at type 1 diabetes diagnosis, adjusted for sex, age group and ethnic minority status

\begin{tabular}{|c|c|c|c|c|c|}
\hline Country & $\begin{array}{l}\text { Year at diabetes } \\
\text { diagnosis }\end{array}$ & Female vs male sex & $\begin{array}{l}\text { Age }<5 \text { years } \\
\text { vs } 10-14.9 \text { years }\end{array}$ & $\begin{array}{l}\text { Age } 5-9.9 \text { years } \\
\text { vs } 10-14.9 \text { years }\end{array}$ & $\begin{array}{l}\text { Ethnic minority vs } \\
\text { non-minority status }\end{array}$ \\
\hline Australia (ADDN) & $1.024(1.002,1.046)$ & $1.014(0.893,1.152)$ & $1.420(1.214,1.660)$ & $0.930(0.795,1.089)$ & $1.123(0.980,1.286)$ \\
\hline Austria & $1.000(0.979,1.021)$ & $1.105(0.974,1.255)$ & $1.157(0.999,1.339)$ & $0.789(0.673,0.927)$ & $1.361(1.188,1.558)$ \\
\hline Czechia $^{\mathrm{a}, \mathrm{b}}$ & $0.995(0.972,1.020)$ & $0.993(0.872,1.130)$ & $1.227(1.048,1.438)$ & $0.911(0.777,1.068)$ & - \\
\hline Denmark & $1.021(0.999,1.044)$ & $1.179(1.027,1.353)$ & $0.911(0.751,1.103)$ & $0.809(0.692,0.947)$ & $1.533(1.255,1.874)$ \\
\hline Germany & $1.011(1.003,1.018)$ & $1.048(1.000,1.098)$ & $1.178(1.112,1.248)$ & $0.868(0.822,0.918)$ & $1.281(1.208,1.358)$ \\
\hline Italy & $0.988(0.980,0.995)$ & $1.039(0.992,1.088)$ & $1.244(1.177,1.315)$ & $0.895(0.846,0.947)$ & $1.170(1.085,1.262)$ \\
\hline Luxembourg & $1.000(0.944,1.059)$ & $1.312(0.968,1.777)$ & $1.743(1.203,2.525)$ & $1.152(0.783,1.695)$ & $1.075(0.774,1.493)$ \\
\hline New Zealand (Auckland) & $1.021(0.982,1.061)$ & $1.187(0.921,1.530)$ & $0.827(0.583,1.173)$ & $0.683(0.505,0.923)$ & $0.881(0.652,1.192)$ \\
\hline Norway & $1.010(0.990,1.031)$ & $1.077(0.949,1.223)$ & $1.055(0.898,1.239)$ & $0.751(0.646,0.872)$ & $1.538(1.262,1.875)$ \\
\hline Slovenia $^{\mathrm{a}, \mathrm{b}}$ & $1.004(0.971,1.037)$ & $1.411(1.126,1.768)$ & $1.076(0.830,1.396)$ & $0.906(0.696,1.179)$ & - \\
\hline Sweden & $1.015(0.999,1.031)$ & $1.057(0.958,1.166)$ & $0.757(0.666,0.86)$ & $0.582(0.516,0.655)$ & $1.567(1.255,1.958)$ \\
\hline USA (SEARCH) & $1.063(1.042,1.085)$ & $0.954(0.891,1.022)$ & $1.234(1.132,1.346)$ & $0.986(0.911,1.068)$ & $1.141(1.063,1.224)$ \\
\hline UK (Wales) & $0.993(0.967,1.020)$ & $0.785(0.664,0.929)$ & $1.368(1.121,1.670)$ & $0.904(0.741,1.105)$ & $1.280(0.933,1.756)$ \\
\hline All countries combined ${ }^{\mathrm{a}}$ & $1.007(1.003,1.011)$ & $1.038(1.012,1.064)$ & $1.176(1.140,1.212)$ & $0.863(0.838,0.889)$ & - \\
\hline
\end{tabular}

Data are presented as prevalence ratio $(95 \% \mathrm{CI})$

${ }^{a}$ Adjusted for sex and age group only

${ }^{\mathrm{b}}$ Information on ethnic minority status not given for this country

in Italy [18] and Australia [19], whereas no changes were found in Austria [14] and Wales [30].

Moreover, as recently reviewed [42], all the abovementioned studies are limited by methodological issues related to their observational designs. However, most studies showed that an awareness campaign targeted to large-scale populations, and interventions targeted to alert primary healthcare to the symptoms of type 1 diabetes, are both feasible and acceptable. Our study did not collect information on local awareness campaigns but showed an increasing trend in the prevalence of DKA at diagnosis of type 1 diabetes over the 11 year period, suggesting that if prevention campaigns had been carried out locally, the expected effect was not achieved. Effective prevention campaigns should be targeted to reach a high percentage of the general population and healthcare professionals, should be repeated and prolonged over time, and should monitor all factors influencing the occurrence of DKA [15]. Preschool screening for islet autoantibodies in the general population might be useful to prevent DKA at diagnosis, as shown in a public health screening programme among children aged 2-5 years in Bavaria, Germany, in which the prevalence of DKA at diagnosis was less than 5\% [43]. Moreover, screening costs were kept low by using a relatively inexpensive and sensitive method.

Differences in DKA prevalence between countries The proportion of children with DKA at diagnosis of type 1 diabetes varies widely between countries. In Europe, the North-South gradient was confirmed by a higher prevalence of DKA in countries with low incidence of type 1 diabetes and in those closer to the equator, compared with countries having a higher incidence of type 1 diabetes and those that are further from the equator $[22,44]$. In addition, higher proportions of DKA are more common in countries with a lower HDI. Our data are consistent with these results, showing an inverse association between DKA prevalence and HDI and geographical latitude.

Sex differences in DKA prevalence In our analysis, the overall proportion of girls presenting with DKA was higher than among boys. Almost all countries showed a slightly higher proportion of girls presenting with DKA at diabetes diagnosis, with the exception of Wales where boys more often presented with DKA at diabetes diagnosis. The reason for the higher incidence of DKA in the male sex [44] but a higher proportion of DKA in the female sex is unclear and calls for further studies. Even if an excess of DKA occurs in girls, as was recently reported in a large series of children with established type 1 diabetes [26], a plausible biological, physiological or clinical explanation is currently very hard to hypothesise. Perhaps girls are more reluctant to see the associated weight loss as problematic and, therefore, do not recognise early symptoms of DKA.

Age differences in DKA prevalence The analysis of this multicentre large dataset confirms the highest risks of DKA occur in younger children in all countries except Sweden, Denmark and New Zealand (Auckland), where the highest prevalence of DKA were registered in adolescents aged 10 14.9 years. These findings could be due to less parental awareness of symptoms in very young age groups, or the reluctance of adolescents to bring their symptoms to parental attention. 
Our results, showing a very high prevalence in children under 3 years of age, are consistent with previous observation of higher DKA risk among the youngest children [21, 25, 39, 45], in whom it may be particularly difficult to recognise signs and symptoms, leading to delayed diagnosis. Moreover, it has been reported that in very young children there is more extensive beta cell destruction at diabetes onset [46], which could be related to a faster and more aggressive disease onset.

\section{Differences in DKA prevalence according to ethnic minority}

status In most countries included in our study, an ethnic minority status was associated with a higher prevalence of DKA at diabetes diagnosis, as reported in previous worldwide studies [21,39]. An ethnic minority status might act as a social and cultural barrier, negatively affecting the awareness of disease, the early recognition of symptoms, and the equity in accessing healthcare services.

Strengths and limitations Strengths of our study include worldwide collaboration, which allowed the collection of data from a large number of cases of type 1 diabetes. Moreover, most of the data used for this study came from populationbased registries or clinical registries with well-defined reference populations. In addition, data collection was based on standard inclusion criteria and consistent definitions of DKA over time. Most countries had data on venous $\mathrm{pH}$ and/or serum bicarbonate levels (11 countries, including 44,617 and 22,426 cases with venous $\mathrm{pH}$ and bicarbonate data, respectively).

Our study has several limitations. Results were based on retrospective data collection and the study period was relatively short, limiting the precision of trend estimates in each country. We only included cases of type 1 diabetes with available information on DKA status, which was the same approach used in similar studies on DKA at diagnosis of type 1 diabetes [24]. Consequently, the exclusion of data from individuals without information on venous $\mathrm{pH}$ and/or bicarbonate might have caused an overestimation of DKA prevalence. However, in more than $80 \%$ of the cases, data for venous $\mathrm{pH}$ or bicarbonate were available. We suspect that physicians do not measure venous $\mathrm{pH}$ or bicarbonate values if clinical symptoms of type 1 diabetes at diagnosis are not severe or, even, absent, since guidelines concerning children [47] do not clearly indicate that measurement of venous $\mathrm{pH}$ and/or bicarbonate is mandatory at diagnosis of type 1 diabetes. If an individual had mild symptoms and was not suspected to have DKA (and, therefore, venous $\mathrm{pH}$ was not measured), that person would have been 'physician diagnosed' as not having DKA. Such evaluation may bias the prevalence estimates, potentially underestimating the observed burden.

While venous $\mathrm{pH}$ and/or bicarbonate provide reliable data on the proportions of new cases presenting with DKA, this might not be possible in all settings and potentially raises cost implications. Serum bicarbonate can be a reliable substitute for venous $\mathrm{pH}$ in settings where access to venous $\mathrm{pH}$ measurement is limited [48]. A basic metabolic profile (including plasma glucose, venous $\mathrm{pH}$ or bicarbonate, blood urea nitrogen, serum creatinine and serum electrolytes) and, preferably, a blood ketone measurement (or, at least, a urine measurement) should be the standard of care for evaluating new-onset diabetes mellitus in a child.

Summary In summary, this analysis of 59,000 children with newly diagnosed type 1 diabetes, from different countries, showed a high prevalence of children presenting with DKA at diabetes diagnosis with large intercountry differences and a slight increase in prevalence over time. Despite the present lack of effective measures to reduce the risk of DKA at diabetes diagnosis, our findings of high prevalence of DKA at diagnosis of diabetes must be considered worrying for all countries and especially for those with access to advanced healthcare systems. These findings should be considered as a call for action to put more effort into promoting an earlier diagnosis of diabetes to prevent DKA in children and adolescents worldwide. Collaborative approaches such as this help gain a better understanding of the prevalence of DKA at diagnosis of diabetes, to inform development of interventions to improve patient outcomes.

Acknowledgements We acknowledge all registries for making data available for this international project: Diabetes Patients Follow-up [DPV; Austria, Germany and Luxembourg; supported by grants from the German Center for Diabetes Research (DZD) and the German Diabetes Association (DDG)]; Czech National Childhood Diabetes Register (ČENDA; supported by grants from the Czech Diabetes Society ČLS JEP and the Czech Ministry of Health [conceptual support project to research organisation 00064203 - FN Motol]); Danish Registry of Childhood and Adolescent Diabetes (DanDiabKids; Denmark); Norwegian Childhood Diabetes Registry (NCDR); Study Group for diabetes of the Italian Society for Paediatric Endocrinology and Diabetes (Italy); Slovenian national diabetes type 1 registry (Slovenia); The Swedish Paediatric Diabetes Quality Registry, SWEDIABKIDS (Sweden); The Wales Paediatric Diabetes registry on behalf of the Brecon Group; Australasian Diabetes Data Network (supported by JDRF Australia, the recipient of the Australian Research Council Special Research Initiative in Type 1 Juvenile Diabetes. A list of the ADDN sites contributing data and ADDN Study Group Investigators is available at http://addn.org.au/); and SEARCH for Diabetes in Youth-US (funded by the Centers for Disease Control and Prevention [PA numbers 00097, DP-05-069 and DP-10-001] and supported by the National Institute of Diabetes and Digestive and Kidney Diseases USA). Part of this study was presented in oral presentation form at the 44th ISPAD Annual Conference, 2018, in Hyderabad, India.

Data availability The dataset for the current study is available on reasonable request by contacting RWH or VC.

Funding Open Access funding provided by Projekt DEAL. This research received no specific grant from any funding agency in the public, commercial or not-for-profit sectors. 
Authors' relationships and activities The authors declare that there are no relationships or activities that might bias, or be perceived to bias, their work.

Contribution statement All authors contributed to the study design, drafting, revising and approval of the final version of the manuscript. $\mathrm{VC}$ researched data and wrote the manuscript and RG wrote the manuscript. JMG and RWH researched data and were responsible for the statistical analysis. KA, NHB, OC, KD, JWG, RH, SEH, CJ, GJ, BRK, EJM-D, ASP, BR-M, US, TS, ZS, JS, JTW, NB and DD researched data, contributed to discussion and reviewed/edited the manuscript. VC is the guarantor of this work and, as such, had full access to all the analysed data in the study; RWH and JMG take responsibility for the integrity of the data and accuracy of the data analysis. All data owners have given permission for publication.

Open Access This article is licensed under a Creative Commons Attribution 4.0 International License, which permits use, sharing, adaptation, distribution and reproduction in any medium or format, as long as you give appropriate credit to the original author(s) and the source, provide a link to the Creative Commons licence, and indicate if changes were made. The images or other third party material in this article are included in the article's Creative Commons licence, unless indicated otherwise in a credit line to the material. If material is not included in the article's Creative Commons licence and your intended use is not permitted by statutory regulation or exceeds the permitted use, you will need to obtain permission directly from the copyright holder. To view a copy of this licence, visit http://creativecommons.org/licenses/by/4.0/.

\section{References}

1. Shrestha SS, Zhang P, Barker L, Imperatore G (2010) Medical expenditures associated with diabetes acute complications in privately insured U.S. youth. Diabetes Care 33(12):2617-2622. https://doi.org/10.2337/dc10-1406

2. Bui H, To T, Stein R, Fung K, Daneman D (2010) Is diabetic ketoacidosis at disease onset a result of missed diagnosis? J Pediatr 156(3):472-477. https://doi.org/10.1016/j.jpeds.2009.10. 001

3. Duca LM, Reboussin BA, Pihoker C, et al (2019) Diabetic ketoacidosis at diagnosis of type 1 diabetes and glycemic control over time: the SEARCH for diabetes in youth study. Pediatr Diabetes 20(2):172-179. https://doi.org/10.1111/pedi.12809

4. Shalitin S, Fisher S, Yackbovitch-Gavan M, et al (2018) Ketoacidosis at onset of type 1 diabetes is a predictor of longterm glycemic control. Pediatr Diabetes 19(2):320-328. https:// doi.org/10.1111/pedi.12546

5. Duca LM, Wang B, Rewers M, Rewers A (2017) Diabetic ketoacidosis at diagnosis of type 1 diabetes predicts poor longterm glycemic control. Diabetes Care 40:1249-1255

6. Fredheim S, Johannesen J, Johansen A, et al, Danish Society for Diabetes in Childhood and Adolescence. (2013) Diabetic ketoacidosis at the onset of type 1 diabetes is associated with future $\mathrm{HbA}_{1 \mathrm{c}}$ levels. Diabetologia 56(5):995-1003. https://doi.org/10. 1007/s00125-013-2850-Z

7. Semenkovich K, Bischoff A, Doty T, et al (2016) Clinical presentation and memory function in youth with type 1 diabetes. Pediatr Diabetes 17(7):492-499. https://doi.org/10.1111/pedi.12314
8. Aye T, Mazaika PK, Mauras N, et al, Diabetes Research in Children Network (DirecNet) Study Group. (2019) Impact of early diabetic ketoacidosis on the developing brain. Diabetes Care 42(3):443449. https://doi.org/10.2337/dc18-1405

9. Knip M, Korhonen S, Kulmala P, et al (2010) Prediction of type 1 diabetes in the general population. Diabetes Care 33(6):1206-1212. https://doi.org/10.2337/dc09-1040

10. Sharp SA, Rich SS, Wood AR, et al (2019) Development and standardization of an improved type 1 diabetes genetic risk score for use in newborn screening and incident diagnosis. Diabetes Care 42(2):200-207. https://doi.org/10.2337/dc18-1785

11. Barker JM, Goehrig SH, Barriga K, et al, DAISY study. (2004) Clinical characteristics of children diagnosed with type 1 diabetes through intensive screening and follow-up. Diabetes Care 27(6): 1399-1404. https://doi.org/10.2337/diacare.27.6.1399

12. Winkler C, Schober E, Ziegler AG, Holl RW (2012) Markedly reduced rate of diabetic ketoacidosis at onset of type 1 diabetes in relatives screened for islet autoantibodies. Pediatr Diabetes 13(4): 308-313. https://doi.org/10.1111/j.1399-5448.2011.00829.x

13. Meehan C, Fout B, Ashcraft J, Schatz DA, Haller MJ (2015) Screening for T1D risk to reduce DKA is not economically viable. Pediatr Diabetes 16(8):565-572. https://doi.org/10.1111/pedi. 12313

14. Fritsch M, Schober E, Rami-Merhar B et al (2013) Diabetic ketoacidosis at diagnosis in Austrian children: a population-based analysis, 1989-2011. J Pediatr 163:1484-1488

15. Derraik JGB, Cutfield WS, Maessen SE et al (2018) A brief campaign to prevent diabetic ketoacidosis in children newly diagnosed with type 1 diabetes mellitus: the NO-DKA study. Pediatr Diabetes 19(7):1257-1262. https://doi.org/10.1111/pedi.12722

16. Hekkala AM, Ilonen J, Toppari J, Knip M, Veijola R (2018) Ketoacidosis at diagnosis of type 1 diabetes: effect of prospective studies with newborn genetic screening and follow up of risk children. Pediatr Diabetes 19(2):314-319. https://doi.org/10.1111/pedi. 12541

17. Fox LA, Mubasher M, Wolfsdorf JI, et al, T1D Exchange Clinic Network. (2016) T1D exchange clinic network. Characteristics of youth with type 1 diabetes (T1D) with and without a parent with T1D in the T1D exchange clinic registry. J Diabetes 8(6):834-838. https://doi.org/10.1111/1753-0407.12363

18. Vanelli M, Chiari G, Ghizzoni L, Costi G, Giacalone T, Chiarelli F (1999) Effectiveness of a prevention program for diabetic ketoacidosis in children. An 8-year study in schools and private practices. Diabetes Care 22(1):7-9. https://doi.org/10.2337/ diacare.22.1.7

19. King BR, Howard NJ, Verge CF et al (2012) A diabetes awareness campaign prevents diabetic ketoacidosis in children at their initial presentation with type 1 diabetes. Pediatr Diabetes 13(8):647-651. https://doi.org/10.1111/j.1399-5448.2012.00896.x

20. Rewers A, Dong F, Slover RH, Klingensmith GJ, Rewers M (2015) Incidence of diabetic ketoacidosis at diagnosis of type 1 diabetes in Colorado youth, 1998-2012. JAMA 313(15):1570-1572. https:// doi.org/10.1001/jama.2015.1414

21. Dabelea D, Rewers A, Stafford JM, et al, SEARCH for Diabetes in Youth Study Group. (2014) Trends in the prevalence of ketoacidosis at diabetes diagnosis: the SEARCH for diabetes in youth study. Pediatrics 133(4):e938-e945. https://doi.org/10.1542/ peds.2013-2795

22. Große J, Hornstein H, Manuwald U, Kugler J, Glauche I, Rothe U (2018) Incidence of diabetic ketoacidosis of new-onset type 1 diabetes in children and adolescents in different countries correlates with human development index (HDI): an updated systematic 
review, meta-analysis, and meta-regression. Horm Metab Res 50(3):209-222. https://doi.org/10.1055/s-0044-102090

23. Neu A, Hofer S, Karges B, Oeverink R, Rosenbauer J, Holl RW (2009) DPV-initiative and the German BMBF competence network for diabetes mellitus ketoacidosis at diabetes onset is still frequent in children and adolescents: a multicentre analysis of 14,664 patients from 106 institutions. Diabetes Care 32(9):1647-1648. https://doi. org/10.2337/dc09-0553

24. Usher-Smith JA, Thompson M, Ercole A, Walter FM (2012) Variation between countries in the frequency of diabetic ketoacidosis at first presentation of type 1 diabetes in children: a systematic review. Diabetologia 55(11):2878-2894. https://doi.org/ 10.1007/s00125-012-2690-2

25. Cherubini V, Skrami E, Ferrito L et al (2016) High frequency of diabetic ketoacidosis at diagnosis of type 1 diabetes in Italian children: a nationwide longitudinal study, 2004-2013. Sci Rep 6:38844

26. Maahs DM, Hermann JM, Holman N et al (2015) Rates of diabetic ketoacidosis: international comparison with 49,859 pediatric patients with type 1 diabetes from England, Wales, the US, Austria, and Germany. Diabetes Care 38:1876-1882

27. Hofer SE, Schwandt A, Holl RW (2016) Standardized documentation in pediatric diabetology: experience from Austria and Germany. J Diabetes Sci Technol 10(5):1042-1049. https://doi. org/10.1177/1932296816658057

28. Clapin H, Phelan H, Bruns L Jr et al (2016) Australasian diabetes data network: building a collaborative resource. J Diabetes Sci Technol 10(5):1015-1026. https://doi.org/10.1177/1932296816648983

29. Skrivarhaug T, Stene LC, Drivvoll AK, Strøm H, Joner G (2014) Incidence of type 1 diabetes in Norway among individuals aged 014 years 1989-2012: has the incidence stopped rising? Results from the Norwegian childhood diabetes registry. Diabetologia 57(1):5762. https://doi.org/10.1007/s00125-013-3090-y

30. Lansdown AJ, Barton J, Warner J, et al, Brecon Group. (2012) Prevalence of ketoacidosis at diagnosis of childhood onset type 1 diabetes in Wales from 1991 to 2009 and effect of a publicity campaign. Diabet Med 29(12):1506-1509. https://doi.org/10. 1111/j.1464-5491.2012.03638.x

31. Svensson J, Cerqueira C, Kjaersgaard P et al (2016) Danish registry of childhood and adolescent diabetes. Clinical epidemiology 8: 679-683. https://doi.org/10.2147/CLEP.S99469

32. Dovc K, Telic SS, Lusa L et al (2014) Improved metabolic control in pediatric patients with type 1 diabetes: a nationwide prospective 12- year time trends analysis. Diabetes Technol Ther 16(1):33-40. https://doi.org/10.1089/dia.2013.0182

33. Šumník Z, Venháčová J, Škvor J, et al, ČENDA Project Group. (2020) Five years of improving diabetes control in Czech children after the establishment of the population-based childhood diabetes register ČENDA. Pediatr Diabetes 21(1):77-87. https://doi.org/10. 1111/pedi.12929

34. United Nations Development Programme (2019) Human development reports. Available from: http://hdr.undp.org/en/data/query. Accessed: 4 May 2019

35. Benjamini Y, Hochberg Y (1995) Controlling the false discovery rate: a practical and powerful approach to multiple testing. J R Statist Soc B 57:289-300

36. Alonso GT, Coakley A, Pyle L, Manseau K, Thomas S, Rewers A (2020) Diabetic ketoacidosis at diagnosis of type 1 diabetes in
Colorado children, 2010-2017. Diabetes Care 43(1):117-121. https://doi.org/10.2337/dc19-0428

37. Benoit SR, Zhang Y, Geiss LS (2018) Trends in diabetic ketoacidosis hospitalizations and in-hospital mortality-United States, 200-2014. Morb Mortal Wkly Rep 67(12):362-365. https://doi.org/10.15585/mmwr.mm6712a3

38. Usher-Smith JA, Thompson MJ, Sharp SJ, Walter FM (2011) Factors associated with the presence of diabetic ketoacidosis at diagnosis of diabetes in children and young adults: a systematic review. BMJ 343:d4092

39. Lévy-Marchal C, Patterson CC, Green A (2001) Geographical variation of presentation at diagnosis of type I diabetes in children: the EURODIAB study. Diabetologia 44(Suppl 3):B75-B80

40. Triolo TM, Chase HP, Barker JM, the DPT-1 Study Group (2009) Diabetic subjects diagnosed through the diabetes prevention trialtype 1 (DPT-1) are often asymptomatic with normal A1C at diabetes onset. Diabetes Care 32(5):769-773. https://doi.org/10.2337/ dc08-1872

41. Elding Larsson H, Vehik K, Bell R, et al, TEDDY Study Group., SEARCH Study Group., Swediabkids Study Group., DPV Study Group., Finnish Diabetes Registry Study Group. (2011) Reduced prevalence of diabetic ketoacidosis at diagnosis of type 1 diabetes in young children participating in longitudinal follow-up. Diabetes Care 34(11):2347-2352. https://doi.org/10. 2337/dc11-1026

42. Deylami R, Townson J, Mann M, Gregory JW (2018) Systematic review of publicity interventions to increase awareness amongst healthcare professionals and the public to promote earlier diagnosis of type 1 diabetes in children and young people. Pediatr Diabetes 19(3):566-573. https://doi.org/10.1111/pedi.12565

43. Ziegler AG, Kick K, Bonifacio E, et al, Fr1da Study Group. (2020) Yield of a public health screening of children for islet autoantibodies in Bavaria, Germany. JAMA 323(4):339-351. https://doi. org/10.1001/jama.2019.21565

44. Patterson CC, Harjutsalo V, Rosenbauer J et al (2019) Trends and cyclical variation in the incidence of childhood type 1 diabetes in 26 European centres in the 25 year period 1989-2013: a multicentre prospective registration study. Diabetologia 62(3):408-417. https:// doi.org/10.1007/s00125-018-4763-3

45. Jefferies C, Cutfield SW, Derraik JG et al (2015) 15-year incidence of diabetic ketoacidosis at onset of type 1 diabetes in children from a regional setting (Auckland, New Zealand). Sci Rep 5:10358

46. Bizzarri C, Benevento D, Ciampalini P et al (2010) Clinical presentation and autoimmune characteristics of very young children at the onset of type 1 diabetes mellitus. J Pediatr Endocrinol Metab 23(11):1151-1157. https://doi.org/10.1515/jpem.2010.180

47. Mayer-Davis EJ, Kahkoska AR, Jefferies C et al (2018) ISPAD clinical practice consensus guidelines 2018: definition, epidemiology, and classification of diabetes in children and adolescents. Pediatr Diabetes 19(Suppl 27):7-19

48. von Oettingen J, Wolfsdorf J, Feldman HA, Rhodes ET (2015) Use of serum bicarbonate to substitute for venous $\mathrm{pH}$ in new-onset diabetes. Pediatrics 136(2):e371-e377

Publisher's note Springer Nature remains neutral with regard to jurisdictional claims in published maps and institutional affiliations. 


\section{Affiliations}

Valentino Cherubini ${ }^{1}$ (D) - Julia M. Grimsmann ${ }^{2,3}$ (D) $\cdot$ Karin Åkesson $^{4,5}$ (D) Niels H. Birkebæk ${ }^{6}$ (D) Ondrej Cinek $^{7}$ (D) Klemen Dovč ${ }^{8}$ (D) $\cdot$ Rosaria Gesuita $^{9}$ (D) John W. Gregory ${ }^{10}$ (D) Ragnar Hanas $^{11,12}$ (D) - Sabine E. Hofer ${ }^{13}$ (D) Reinhard W. Holl ${ }^{2,3}$ (D) . Craig Jefferies ${ }^{14}$ (D) $\cdot$ Geir Joner ${ }^{15,16}$ (D) B Bruce R. King ${ }^{17}$ (D) - Elizabeth J. Mayer-Davis ${ }^{18}$ (D) Alexia S. Peña ${ }^{19}$ (D) B Birgit Rami-Merhar ${ }^{20}$ (D) - Ulrike Schierloh ${ }^{21}$ (D) $\cdot$ Torild Skrivarhaug $^{15,16}$ (D) Zdenek Sumnik $^{7}$ (D) Jannet Svensson ${ }^{22}$ (D) - Justin T. Warner ${ }^{23} \cdot$ Nataša Bratina $^{8}$ (D) $\cdot$ Dana Dabelea ${ }^{24}$ (D)

1 Division of Pediatric Diabetology, Department of Women's and Children's Health, Salesi Hospital, Ancona, Italy

2 Institute of Epidemiology and Medical Biometry, ZIBMT, University of Ulm, Albert-Einstein-Allee 41, 89081 Ulm, Germany

3 German Center for Diabetes Research (DZD), MunichNeuherberg, Germany

4 Department of Biomedical and Clinical Sciences, Linköping University, Linköping, Sweden

5 Department of Pediatrics, Ryhov County Hospital, Jönköping, Sweden

6 Department of Pediatrics, Aarhus University Hospital, Aarhus, Denmark

7 Department of Pediatrics, 2nd Faculty of Medicine, Charles University in Prague and Motol University Hospital, Prague, Czechia

8 Department of Paediatric Endocrinology, Diabetes and Metabolic Diseases, UMC - University Children's Hospital and Faculty of Medicine, Ljubljana, Slovenia

9 Centre of Epidemiology and Biostatistics, Polytechnic University of Marche, Via Tronto 10/a, 60020 Ancona, Italy

10 Division of Population Medicine, School of Medicine, Cardiff University, Cardiff, UK

11 Department of Pediatrics, NU Hospital Group, Uddevalla, Sweden

12 Sahlgrenska Academy, Institute of Clinical Sciences, Gothenburg University, Gothenburg, Sweden
13 Department of Pediatrics 1, Medical University of Innsbruck, Innsbruck, Austria

14 Department of Endocrinology, Starship Children's Health, Auckland, New Zealand

15 Division of Paediatric and Adolescent Medicine, Oslo University Hospital, Oslo, Norway

16 Institute of Clinical Medicine, University of Oslo, Oslo, Norway

17 Department of Paediatric Diabetes, John Hunter Children's Hospital, Faculty of Medicine, University of Newcastle, Newcastle, NSW, Australia

18 Departments of Nutrition and Medicine, University of North Carolina, Chapel Hill, NC, USA

19 Paediatrics, Robinson Research Institute, The University of Adelaide, Adelaide, SA, Australia

20 Department of Pediatric and Adolescent Medicine, Medical University of Vienna, Vienna, Austria

21 DECCP, Clinique Pédiatrique, Centre Hospitalier, Luxembourg, Luxembourg

22 Department of Pediatrics and Adolescent Medicine, Copenhagen University Hospital, Herlev, Denmark

23 Department of Child Health, University Hospital of Wales, Cardiff, UK

24 Lifecourse Epidemiology of Adiposity and Diabetes (LEAD) Center, Colorado School of Public Health, University of Colorado Anschutz Medical Campus, Aurora, CO, USA 